\title{
Human Langerhans cell in a dermal lymphatic vessel
}

Kristian Pfaller, Department of Histology and Molecular Cell Biology, University of Innsbruck, Austria, kristian.pfaller@uibk.ac.at

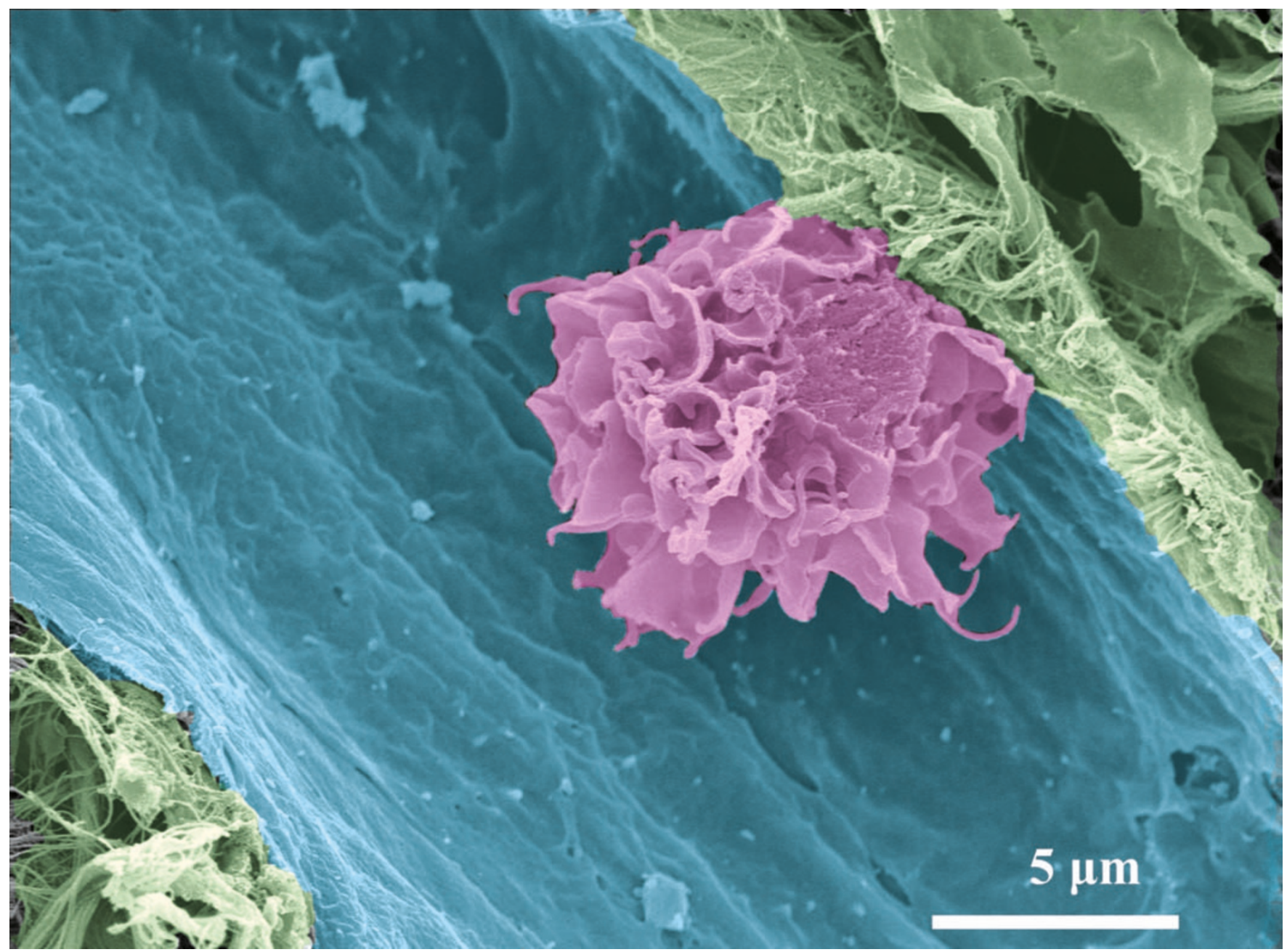

Purple and blue pseudo-colouring represent the dendritic cell and the lymphatic vessel, respectively. The specimen was obtained using a field emission scanning electron microscope (DSM 982 Gemini, Zeiss). Scale bar represents $5 \mu \mathrm{m}$.

The winner would like to acknowledge the help of Lukas A. Huber and Patrizia Stoitzner, Department of Histology and Molecular Cell Biology, University of Innsbruck, Austria. 